Arqueología y Sociedad,

№ 19,2008

YCHSMA AMZHOY

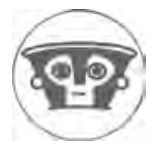

\title{
Poder y JERARQUías YCHSMAS EN EL VALLE DE LURÍN
}

\author{
Peter Eeckhout *
}

\begin{abstract}
Resumen
La definición de la forma de autoridad que dominaba el valle de Lurín y los valles vecinos durante los periodos tardios sigue siendo un objeto de debate. Las fuentes etnohistóricas han sido masivamente usadas para reconstruir el paisaje socio-político regional antes de los Incas. Aunque ciertos autores defienden un modelo de poder teocrático dominado por los sacerdotes del culto de Ychsma-Pachacamac. Otros proponen una división de la autoridad entre sacerdotes y curacas, sea entre religioso y secular. La arquitectura monumental y los modelos de asentamientos proporcionan datos interesantes para nutrir este debate. Concretamente, comparamos los dichos datos arqueológicos con las informaciones recogidas en el valle de Lurín antes de las reformas de Toledo. Confirma que lo que importaba fueron los curacas, sus subdivisiones y jerarquías, donde no hay relación con lo religioso, sino más bien con los aspectos más seculares del poder (territorio y tributo). La comparación permite reconstruir el organigrama del poder en la zona y ver como esto se concretiza en el campo, tanto por el diseño de las estructuras arquitectonicas como del tamaño relativo de los grupos sociales involucrados en los varios niveles de poder, asi como la evolución probable destos a lo largo del tiempo.
\end{abstract}

\section{Palabras claves}

Pachacamac, Ychsma, Lurín, Arqueología, Etnohistoria.

\begin{abstract}
The definition of the form of authority that was dominating the Lurín and neighboring valleys during the late periods continues being an object of debate. Ethnohistorical sources have been massively used to reconstruct the socio-political regional framework before the Incas. Though certain authors defend a model of theocratic power dominated by the priests of Ychsma-Pachacamac's cult, others propose a division of the authority between priests and curacas, i.e. between religious and secular. Monumental architecture and settlement patterns provide interesting information to feed this debate. Concretely, I compare this set of archaeological data with the information gathered in the Lurín valley before the reforms of Toledo. It confirms the importance of curacas, their subdivisions and hierarchies, and the absence of link with the religious sphere, but rather with the most secular aspects of power (territory and tribute). The comparison allows to reconstruct the flowchart of power in the zone and to see how it was materialized in the field, so much for the design of the architectural structures as for the relative size of the social groups involved in different levels of power, and their probable evolution through time.
\end{abstract}

\section{Keywords}

Pachacamac, Ychsma, Lurín, Archaeology, Ethnohistory.

* Département Histoire, Art et Archéologie. Université Libre de Bruxelles, Av. F. Roosevelt 50 (CP175) 1050 Brussels, Belgium. Correo electrónico: peeckhou@ulb.ac.be 
La costa central (y el valle de Lurín) es una de las zonas mejor documentadas del Perú antiguo, tanto a nivel de la investigación arqueológica (Cornejo 2000; Eeckhout 1999, 2004a ; Feltham 1983) como de los datos etnohistóricos (Dávila Briceño 1881; Espinoza Soriano 1964, 1974 ; Paredes Botoni 1995, 2004 ; Rostworowski 1972, 1992, 1999 ; Spalding 1984) y de las creencias religiosas (Arriaga 1999; Avila 1987; Duviols 1967).

Desafortunadamente, como ya tuve oportunidad de subrayarlo (Eeckhout 2004b), estas fuentes han sido usadas de manera bastante aleatoria o subyectiva por mucho tiempo, siendo el peso de los textos coloniales en las interpretaciones y descripciones del pasado pre-conquista y pre-inca demaciado grande respecto a los demás registros, especialmente arqueológico.

El problema mayor es la falta de metodología adecuada en el uso de los datos, En consecuencia no se tiene a la fecha una imagen clara de la organización social de los ychsmas que vivieron en la costa central durante los periodos prehispanicos tardios.

En el marco de este artículo, propongo esbozar la dicha organización, usando de las fuentes materiales y escritas. Me dedicaré primeramente al análisis del documento escrito mas importante al respecto, la visita de Andrade de 1573. Después presentaré los datos salientes del estudio del modelo de asentamientos en el valle de Lurín. Veremos en seguida de que manera se puede combinar estos análisis para reconstituir la estructura del poder ychsma y su jerarquía en el valle de Lurín.

\section{DATOS ETNOHISTÓRICOS}

La visita de Andrade es el documento más completo respecto al tema de estudio, pero afortunadamente no el único, así que de alguna manera se puede cruzar y comparar las informaciones de varias fuentes, así como de los autores modernos que han tratado del tema, principal- mente María Rostworowski (1999, quien editó la visita), Ponciano Paredes Botoni (1995, 2004, quien usó la visita y otros documentos y archivos para reconstituir la trayectoria de los linajes dominantes del Lurín en el periodo colonial) y Waldemar Espinoza (1964), quién contribuyó en un estudio pluridiciplinario en el valle, hace medio siglo y recopiló, entre otros, fuentes documentales.

Si empezemos con la visita de 1573 , podemos ya precizar una serie de informaciones muy interesantes (Cuadro 1). Ante todo, me parece relevante detallar el proceso que ha sido usado para realizar este cuadro: en un primer paso, hice una revisión sistemática de todos los datos vinculados con las relaciones de poder, autoridad, y lazos de parentezco en los testimonios, así como los nombres y edad de los testigos. El lector interesado puede referirse de manera muy fácil a las informaciones mencionadas, pues las páginas están precizamente indicadas. Estos datos han sido sintetizados en el cuadro siguiente (Cuadro 2), enfocando sobre los títulos y cargas con los cuales los testigos se presentan. Resaltan de manera obvia dos elementos fundamentales. Primero, existe una estructura jerárquica que contó por lo menos con tres niveles de lideres: el nivel superior con un jefe que domina a todas las parcialidades del valle: Caringas, Anan Ychsma y Hurin Ychsma (Fig.1). El nivel medio con los jefes de estas parcialidades, y un nivel inferior con jefes de asentamientos como $\mathrm{Pa}$ chacamac (asentamiento mayor de los Anan Ychsma, actual pueblo de Pachacamac, que no se debe confundir con el gran centro costeño).

El segundo elemento resaltante es la bipartición sistemática de cada carga, y esto a cada nivel de poder (Fig.2). Esto se ve tanto en el nivel superior con Don Luis Loyan y Alonso Sabat, citados como curacas principales, hasta el nivel de asentamientos, pues el pueblo de $\mathrm{Pa}$ chacamac estuvo mandado conjuntamente por Alonso Choque Guamani y Martin Cacho Ma- 
Cuadro 1. Datos procediendo de la visita de Andrade (1573).

La paginación corresponde a la edición de Rostworowski (1999)

\begin{tabular}{|c|c|c|c|c|}
\hline Nombre & Título/carga & Edad & comentario & Pagina \\
\hline \multirow{9}{*}{ Don Luis Loyan } & cacique de la parcialidad de Anan Ychsma & 33 & & 49 \\
\hline & cacique gobernador deste repartimiento & & & \\
\hline & cacique de la parcialidad de Anan Ychsma & & Hijo de Hernando Llaxa Guayco & $64,71,81$ \\
\hline & & & $\begin{array}{l}\text { Obedecido por Alonso Sabat, cacique } \\
\text { principal }\end{array}$ & 66 \\
\hline & cacique de Pachacamac & & Imponia corveas a los Caringas & 79 \\
\hline & cacique de los Caringas & & contemporaneo de Alonso Sabat & 91 \\
\hline & cacique de Pachacamac & & $\begin{array}{l}\text { Habla en nombre de los demas indios } \\
\text { principales deste valle de Pachacamac }\end{array}$ & 143 \\
\hline & cacique & & & 151 \\
\hline & gobernador del cacicazgo & & segun Alonso Sabat & 100 \\
\hline \multirow[t]{3}{*}{ Alonso Sabat } & cacique principal & & ?del Rímac? & $69,151,154,155$ \\
\hline & & & Generación posterior a Llaxa Guayca & \\
\hline & $\begin{array}{l}\text { cacique principal del repartimiento de } \\
\text { Pachacamac }\end{array}$ & 22 & & 99,114 \\
\hline \multirow[t]{4}{*}{$\begin{array}{l}\text { Hernando Llaxa } \\
\text { Guayco }\end{array}$} & A quien obedecian todas las parcialidades & & Fallecido hacia 1565 & 66 \\
\hline & Intervenia en la justicia entre los Caringas & & & 76 \\
\hline & cacique principal & & De la generación anterior & 156 \\
\hline & $\begin{array}{l}\text { Intervenia en la justicia en el valle de } \\
\text { Pachacamac }\end{array}$ & & $\begin{array}{l}\text { De la epoca de Gonzalez el } \\
\text { encomendero }\end{array}$ & 164 \\
\hline \multirow[t]{5}{*}{ Juan Cuchiguaylle } & $\begin{array}{l}\text { indio principal de la parcialidad de Anan } \\
\text { Ychsma }\end{array}$ & 55 & & 52,114 \\
\hline & principal de la parcialidad de Anan Ychsma & & & 71 \\
\hline & principal del repartimiento de Pachacamac & & & 82 \\
\hline & principal (dependiendo de Loyan?) & & época de Gonzalez de Ruiz & 152 \\
\hline & cacique de Pachacamac & & & $188-9$ \\
\hline \multirow[t]{3}{*}{$\begin{array}{l}\text { Alonso Choque } \\
\text { Guamani }\end{array}$} & $\begin{array}{l}\text { indio de la parcialidad de Anan Ychsma } \\
\text { Caringa }\end{array}$ & 60 & & 53 \\
\hline & $\begin{array}{l}\text { indio principal -cacique de la parcialidad de } \\
\text { Caringas del repartimiento de Pachacamac }\end{array}$ & & Loyan gobernaba este repartimiento & 118 \\
\hline & principal de los Caringas & & Generación anterior & 156 \\
\hline \multirow[t]{2}{*}{ Francisco Mallina } & $\begin{array}{l}\text { indio de los pueblos de Pachacamac de la } \\
\text { parcialidad de Anan Ychsma }\end{array}$ & 45 & & 55 \\
\hline & $\begin{array}{l}\text { indio principal de los deste pueblo de } \\
\text { Pachacamac }\end{array}$ & & & 115 \\
\hline \multirow[t]{2}{*}{ Leandro Caucalla } & indio de la parcialidad de Anan Ychsma & 36 & & 55 \\
\hline & indio del pueblo de Pachacamac & & & \\
\hline Geronimo Calanco & $\begin{array}{l}\text { indio principal y governador de la parcialidad } \\
\text { ee Hurin Ychsma }\end{array}$ & 32 & & 96 \\
\hline \multirow[t]{8}{*}{$\begin{array}{l}\text { Martin Cacho } \\
\text { Macan }\end{array}$} & principal del repartimiento de Pachacamac & 22 & & 58 \\
\hline & cacique principal & & & 69,89 \\
\hline & principal & & & 69 \\
\hline & & & hijo de Hernando Llaxa Guayco & 89 \\
\hline & cacique del pueblo de Pachacamac & & & 116 \\
\hline & cacique & & & 151 \\
\hline & cacique y alcalde & & & \\
\hline & principal & & de los Caringas? & 155 \\
\hline Erancisco Gomez & morador del repartimiento de Pachacamac & & español & 59,116 \\
\hline Pocarasca & principal de Ela (los Reves & & hijo de Sabat & 69 \\
\hline $\begin{array}{l}\text { Aysayco y } \\
\text { Paquincorca }\end{array}$ & principal de Ela (los Reyes & & Hijo de Sabat & 69 \\
\hline Chamot Saba & cacique principal & $*$ & $\begin{array}{l}\text { Epoca de la primera encomienda } \\
\text { (Horgoñez }\end{array}$ & 72 \\
\hline Tauri Chumbi & principal & * & $\begin{array}{l}\text { Epoca de la primera encomienda } \\
\text { (Horgoñez }\end{array}$ & 72 \\
\hline Alonso Sabat & & & Generación posterior a Llaxa Guayca & 81 \\
\hline Pedro Chumbizca & $\begin{array}{l}\text { indio de la parcialidad de Hurin Ychsma del } \\
\text { repartimiepto de Pachacamac }\end{array}$ & 50 & & $82,115,152$ \\
\hline $\begin{array}{l}\text { Pedro } \\
\text { Puertocarrero }\end{array}$ & vecino de la ciudad cuzco & & & 82 \\
\hline Don Domingo & cacique de Hurin & & $\begin{array}{l}\text { En pleito con Pedro Puertocarrero } \\
\text { (época de don Luis Loyan) }\end{array}$ & 101 \\
\hline & cacique de Hurin & & Generación anterior a la presente & \\
\hline Alonso Maca Yauri & cacique & & & 152 \\
\hline & cacique de los indios Caringas & & & 154 \\
\hline & principal de los Caringas & & & 155 \\
\hline
\end{tabular}

* Ya muerto en 1572 
Cuadro 2. Cargas y encargados en 1573 según la visita de Andrade.

\begin{tabular}{|c|c|c|c|c|c|}
\hline & $\begin{array}{c}\text { Cacique } \\
\text { principal de } \\
\text { Pachacamac y } \\
\text { Caringas }\end{array}$ & $\begin{array}{l}\text { Cacique } \\
\text { de Anan } \\
\text { Ychsma }\end{array}$ & $\begin{array}{c}\text { Cacique } \\
\text { de los } \\
\text { Caringas }\end{array}$ & $\begin{array}{l}\text { Cacique } \\
\text { de Hurin } \\
\text { Ychsma }\end{array}$ & $\begin{array}{l}\text { Cacique del } \\
\text { pueblo de } \\
\text { Pachacamac }\end{array}$ \\
\hline Don Luis Loyan & $\mathrm{X}$ & $\mathrm{X}$ & $\mathrm{X}$ & & \\
\hline Alonso Sabat & $\mathrm{X}$ & & & & \\
\hline Juan Cuchigualla & & $\mathrm{X}$ & & & \\
\hline $\begin{array}{l}\text { Alonso Choque } \\
\text { Guamani }\end{array}$ & & & $\mathrm{X}$ & & \\
\hline $\begin{array}{l}\text { Alonso Maca } \\
\text { Yauri }\end{array}$ & & & $\mathrm{X}$ & & \\
\hline $\begin{array}{l}\text { Geronimo } \\
\text { Calanco }\end{array}$ & & & & $\mathrm{X}$ & \\
\hline Don Domingo & & & & $\mathrm{X}$ & \\
\hline $\begin{array}{l}\text { Martin Cacho } \\
\text { Macan }\end{array}$ & & & & & $\mathrm{X}$ \\
\hline Francisco Mallina & & & & & $\mathrm{X}$ \\
\hline
\end{tabular}

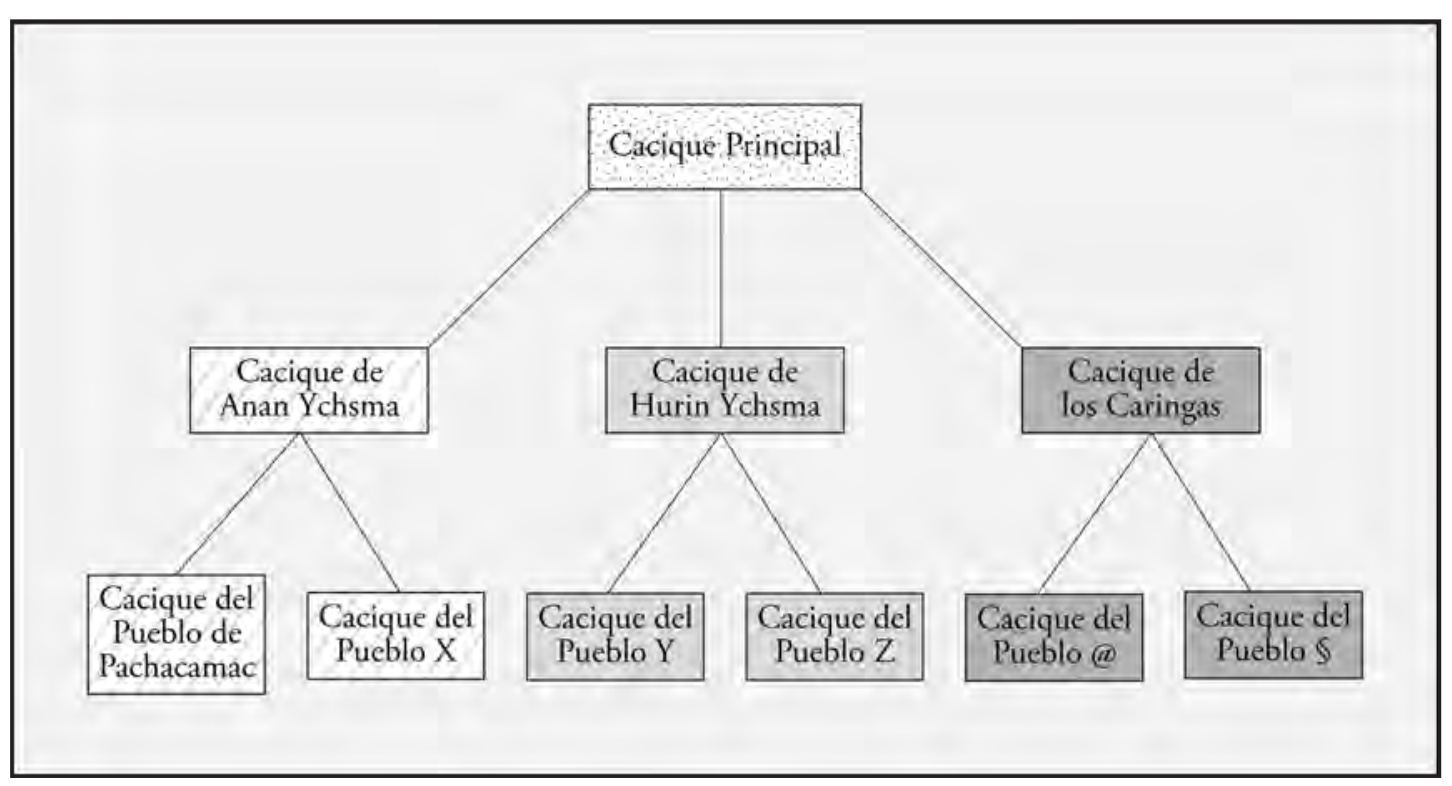

Figura 1. 


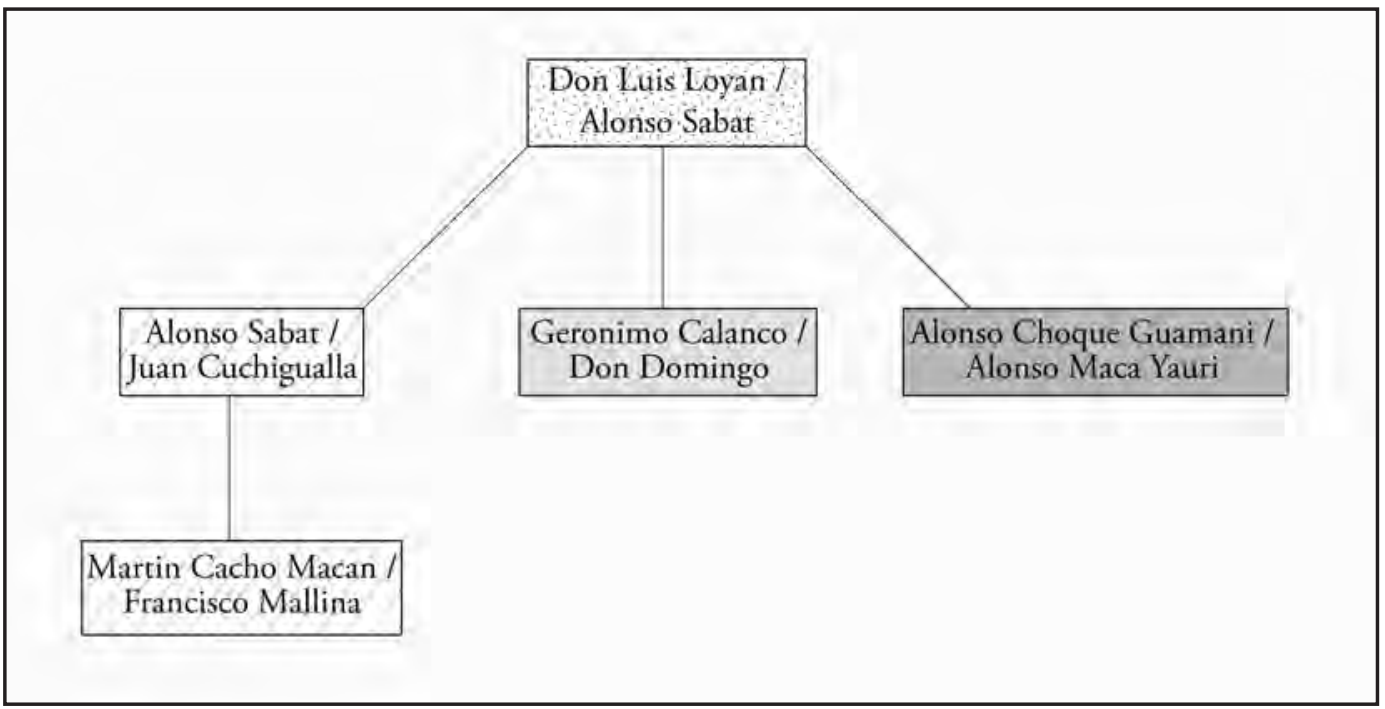

Figura 2.

can. Además, si entramos en los detalles de los testimonios, donde se describen las relaciones entre todos estos personajes en 1573, aparece claramente que los dos jefes que compartían una misma carga no estuvieron la misma gerarquía, o sea, uno mandaba al otro. Es el caso de Luis Loyan quien mandaba a Alonso Sabat. Asi se menciona explicitamente en la visita (cf Cuadro 1). Tenemos pues en el caso de Lurín un ejemplo claro del curaca principal y segunda persona, tal como se conoce en la Costa Central y en la Costa Norte (cf Netherly 1990). Esto se debe entender en el marco general de bipartición, cuadripartición y dualismo que también se observa en los asentamientos y en las divisiones sociales entre los grupos humanos.

También en la visita se menciona a gentes ya fallecidos en 1573, así como sus relaciones de parentezco y descendientes (Fig.3). Por ejemplo, Don Luis Loyan es un hijo de Hernándo Llaxahuyaca, quien fue también curaca principal del valle a la llegada de los Españoles. Chamot Sabat al parecer fue la segunda persona de Hernándo Llaxahuayca, y uno de sus hijos, Alonso, le sucedió en esta carga ${ }^{1}$. Vemos también que los demás hijos de ambos curacas tuvieron cargas, aunque menos importantes. Aparece pues que las cargas se transmiten de una generación a la otra, y que se reproduce también el organigrama ancestral del poder en la región. Es interesante remarcar, como lo hace Rostworowski (1999:18), "(...) que a la muerte de un miembro del poder dual, se elegía a un nuevo personaje, sin que el otro curaca tuviese que renunciar". A la fecha no conocemos este organigrama por completo, pero los datos disponibles son suficientemente coherentes como para sostener el modelo descrito.

Otro elemento que llama la atención es que la descripción de cargas de todos los curacas abarca los campos políticos, económicos y judiciales, pero en ningún momento se hace mención de los aspectos religiosos. Esto ha sido notado por Rostworowski (1999) y Paredes (2004). Por supuesto, podemos pensar que en tiempos de représion de cultos y creencias tradicionales por parte del poder colonial los indigenas hayan preferido ocultar estos aspectos

1 Segun ciertas evidencias, es posible que Llaxahuayca hubiera mandado los valles de Rímac y Lurín, mientras Sabat mandaba el Lurín bajo su autoridad ( Rostworowski 1978:51). 


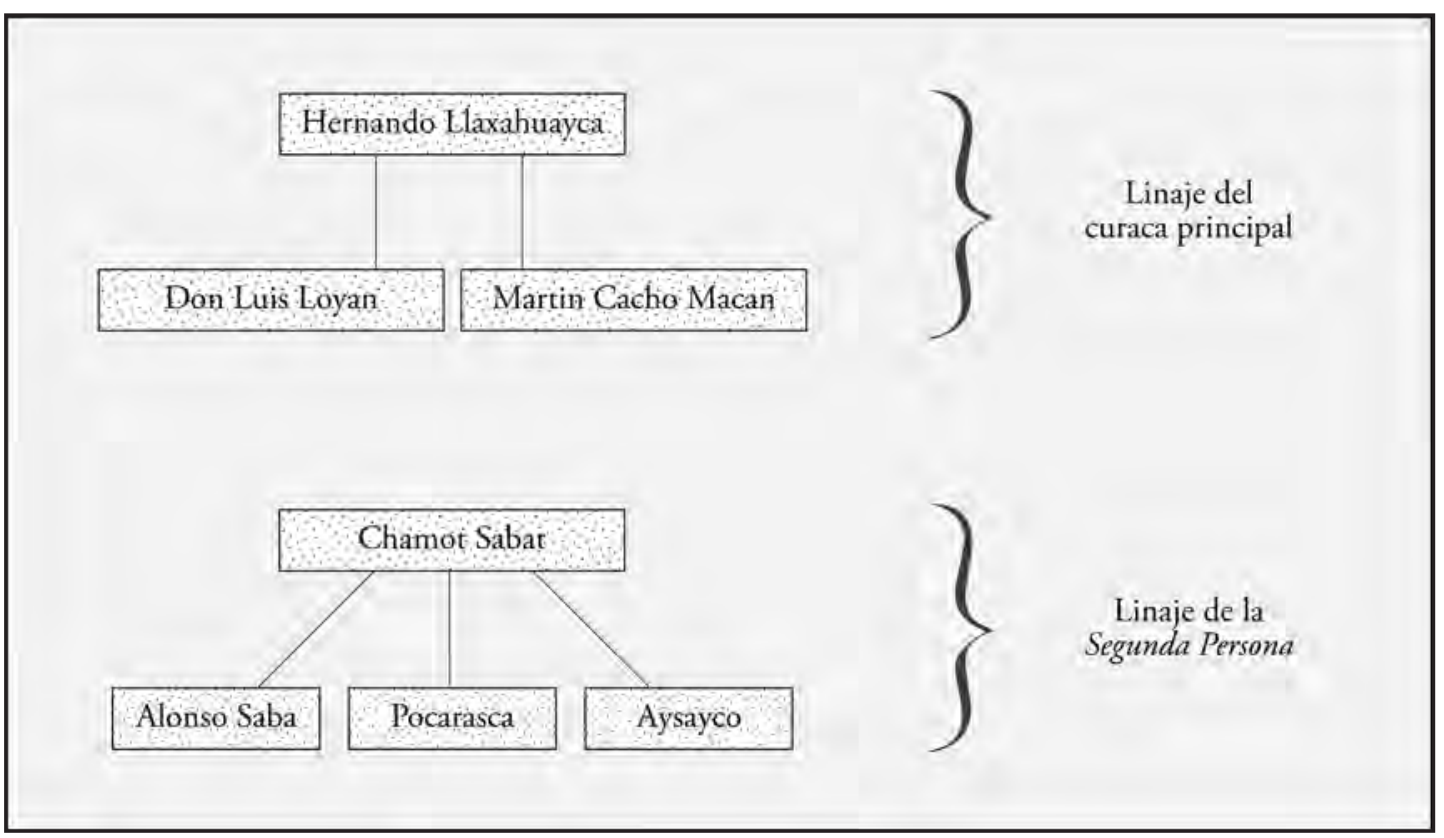

Figura 3.

(Duviols 2003:23), pero se debe recordar que el motivo principal de la Visita de Andrade fue de comprobar el grado de evangelización en la encomienda, pues estuvo notoriamente casi nulo (Rostworowski 1999:9). Por lo tanto, uno puedo pensar que, con la notable excepción del sanctuario de Pachacamac, el valle había preservado sus estructuras tradicionales de poder, las cuales tenían por separado la esfera religiosa y la esfera secular. Podemos pues deducir que los sacerdotes y los curacas formaban dos clases diferentes. La primera fuertamente reprimida por los Españoles. La segunda mantenida en sus funciones según los intereses del gobierno colonial.

El testamento de Alonso Sabat, fechado de 1584, es otro documento muy a menudo citado (Espinoza 1964:136 ; Matos Mar 1964:19; Paredes Botoni 2004). Llama la atención la subdivisión socio-territorial que Sabat describe, pues es algo diferente de lo que acabamos de ver. Cuatro ayllus conformando el Señorio de Ychsma compartían el valle bajo de Lurín desde la costa hasta Cieneguilla: los Pachacamac, los Manchay, los Caringas y los Quilcaycunas.
En términos territoriales, se distribuían de la siguiente manera:

ayllu Pachacamac: desde el grán sitio costeño hasta el pueblo actual de Pachacamac, el cual fue fundado poco tiempo después de la visita de Andrade en el marco general de las reducciones toledanas.

ayllu Manchay: desde el pueblo actual de Pachacamac hasta Cieneguilla.

ayllu Caringa: en la periferie del valle, hacia el súr, hasta las «lomas de Caringa» por Chilca (Mujica 1997)

ayllu Quilcaycuna : entre el litoral y el pueblo actual de Lurín. Este ayllu creó al pueblo de San Pedro de Quilcay, primer nombre del pueblo actual de Lurín (Espinoza 1964:136; Matos Mar 1964:19).

¿Qué sabemos con respecto a los ayllus mencionados?

Los pachacamac aparecen en la lista de los que llevaban ofrendas al díos serrano Pariacaca, así como "...todos los yuncas dese río [el Rímac] y todos los del otro río [el Lurín] (...)" (Avila 1987: cap. 9: 189). Diversos datos sugieren un sistema 
socio-político dual y una división Anan / Hurin entre los Pachacamac. Según Rostworowski (1978:134-35), existían dos pueblos, sea el centro ceremonial con los monumentos (mitad hurin) y un asentamiento ubicado en la margen, opuesta (izquierda), con murallas y estructuras conocidas bajo el nombre de Huaca Candela, donde residía la gente del común. Los españoles hubieran respectado esta antigua partición cuando fundaron el pueblo de San Pedro de Lurín, en la margén izquierda, donde se encontraba el curaca principal en la época colonial, mientras la aldea de San Salvador de Pachacamac, creada en el marco de las reducciones toledanas, fue subordinada a la de Lurín y, dice el autor, "habitada probablemente por los Anan Ychma"(Rostworowski 1978:135 ; 1992:80, 92). Veremos más adelante como estas sugerencias y deducciones se acuerdan con nuestro análisis.

Alborñoz (1967: 33-35) señala que los Manchay tenían como huaca una piedra de forma humana ("como indio") que llamaban Aysaculca y consideraban como pacarisca, es decir fundadora de su linaje o ayllu. No se sabe mucho respecto a los Manchay, salvo que una quebrada del bajo Lurín lleva este nombre, y contiene vestigios prehispánicos. Se ha identificado reiteradamente este sitio como sede del ayllu Manchay (Bueno Mendoza 1974/75:179; Espinoza Soriano 1964:136; Negro 1977:204). Se sabe ahora que el sitio de Manchay Bajo corresponde al Periodo Formativo (Burger y Salazar- Burger 1992:123). Los manchay de los periodos tardios pues se encontraban en otro lugar. Sobre la base de las investigaciones llevadas en el valle, opino que vivían en el sitio de Pampa de las Flores, frente a la quebrada de Manchay, en la margen izquierda del río (Eeckhout 1997;1999a;1999b;1999c;2003).

Rostworowski (1992:96-7), referiendose a un documento inedito (Retasa Toledana de Huarochiri a cargo de Rodrigo Cantos de Andrade, 1577) señala que existía una guaranga yunga de Sisicaya incorporada a las guarangas serranas de Huarochirí y sugiere que constaba de Caringas lomeros, conformando tal vez un especie de enclave. "Esta anexión fue seguramente una consecuencia de la conquista inca, y obedece quizás a un pedido de los yauyos, amigos de los soberanos cusqueños, deseosos de tener acceso a una zona del chaupi yunga o costa media y a una medio ambiente apropiado para las plantaciones de cocales, de gran valor para los habitantes de las serranías contiguas" (Rostworowski 1992:97). Los Caringas son también explicitamente mencionados en la lista de las etnías que venían regularmente a visitar el santuario de Pariacaca con ofrendas (Avila 1987: cap.9:189).

Los Quilcaycunas fueron pescadores quienes ocupaban la parte del litoral alrededor de la playa San Pedro -al sur del Lurín-, y quizas pescaban también por el norte, en las playas del señorío de Maranga, según el principio de archipelago horizontal (Rostworowski 1978 93; 1992:93-95). Según Bueno Mendoza (1974/75:179), los Quilcaycunas conformaban probablemente un grupo de imigrantes desplazado por fuerza durante el incanato, es decir, una mitma. Esto explicaría porque su territorio está incluido en el territorio de los PachacamacUrin Ychsma, pero también explica porque no se hace mención de ellos en 1573: los Quilcaycunas, como mitmas incas, no estuvieron sometidos a la autoridad local sino imperial, y por lo tanto no dependían de los jefes tradicionales ychsmas en la epoca colonial temprana (Negro 1977:205; Salinas y Cordova 1957: 69). Creo que lo mismo se puede aplicar a la mitma de Yauyos procedentes de Huarochiri quienes fundaron el sitio de Pueblo Viejo (cf Makowski 2002:165).

\section{Datos ARQueológicos}

Los datos ethnohistóricos sugieren que la autoridad se organizaba sobre la base de los principios de jerarquía y dualidad. Este sistema 
es similar a los de mitades, donde una mitad manda a la otra, esto en funcion de los niveles de autoridad. Cada "nivel de autoridad" pues estaría en manos de dos jefes, uno beneficiaba de ciertas prerrogativas respecto al otro. En terminos concretos, estas prerogativas pueden expresarse por el acceso a una fuerza de trabajo mas grande (Kendall 1985:139, Netherly 1990 Rostworowski 1989:254). "Este modelo etnohistórico tiene una consecuencia obvia para las manifestaciones arqueológicas del dualismo: el poder compartido puede reflejarse en una jerarquía asimétrica de los asentamientos" (Moore 1995:174). En el valle de Nepeña en el Periodo Intermedio Tardío, el asentamiento mayor es dos veces más grande que el segundo asentamiento, el cual a su vez es dos veces mas grande que la clase siguiente de asentamientos. Las proporciones concuerdan a groso modo con lo que se pude esperar si un cacique principal tenía acceso al doble de la fuerza de trabajo de una segunda persona, y esto se repite en todos los rangos de asentamientos (id:175). La aplicación de este método al valle bajo de Lurín se revela muy instructiva (Figs 4, 5). En el valle bajo pues, el sitio de Pachacamac, único en su categoria, tiene una superficie que es el doble, aproximadamente, que el de Pampa de Flores² ${ }^{2}$ Los sitios de Panquilma y Huaycán abarcan cada uno una superficie que corresponde más o menos a la mitad de la de Pampa de Flores. Dos sitios (Tijerales y molle) conforman la categoría inferior. Luego vienen Chontay y Río Seco (poco más de 4ha). Cuarenta y dos sitios de menos de 4 ha representan el conjunto de pequeños sitios locales que se puede comparar a aldeas. Si seguimos el modelo sugerido por Moore, Pampa de Flores constituiría la residencia del jefe asociado - pero inferior- al jefe de Pachacamac. Panquilma y Huaycán serían las residencias de los jefes de dos territorios distintos. El primero, teniendo como "segunda persona” el Señor de Tijerales, el otro, el jefe

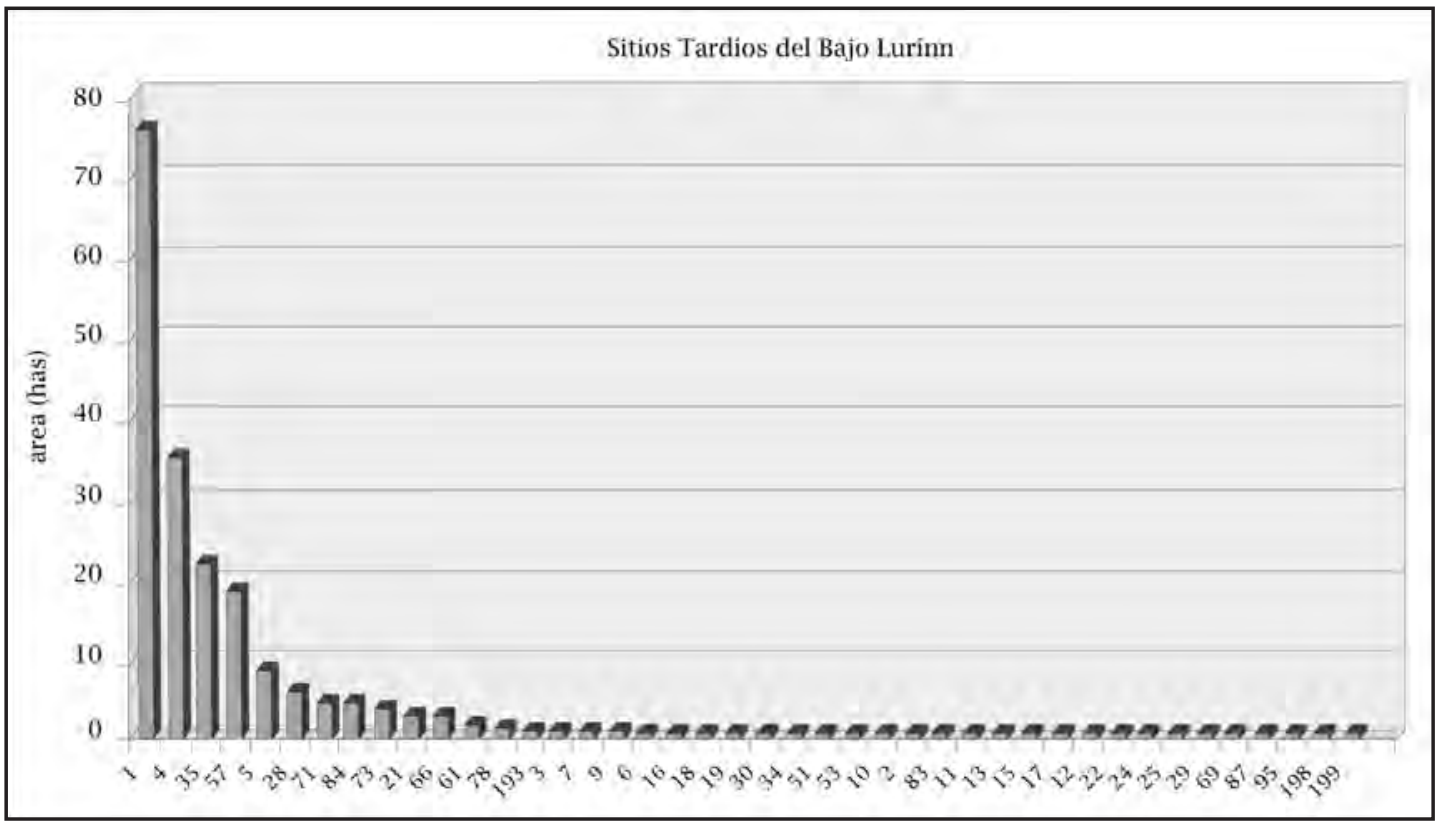

Figura 4.

2 Superficie estimada para las estructuras monumentales al fin del Periodo Intermedio Tardío (cf Eeckhout 1999). 


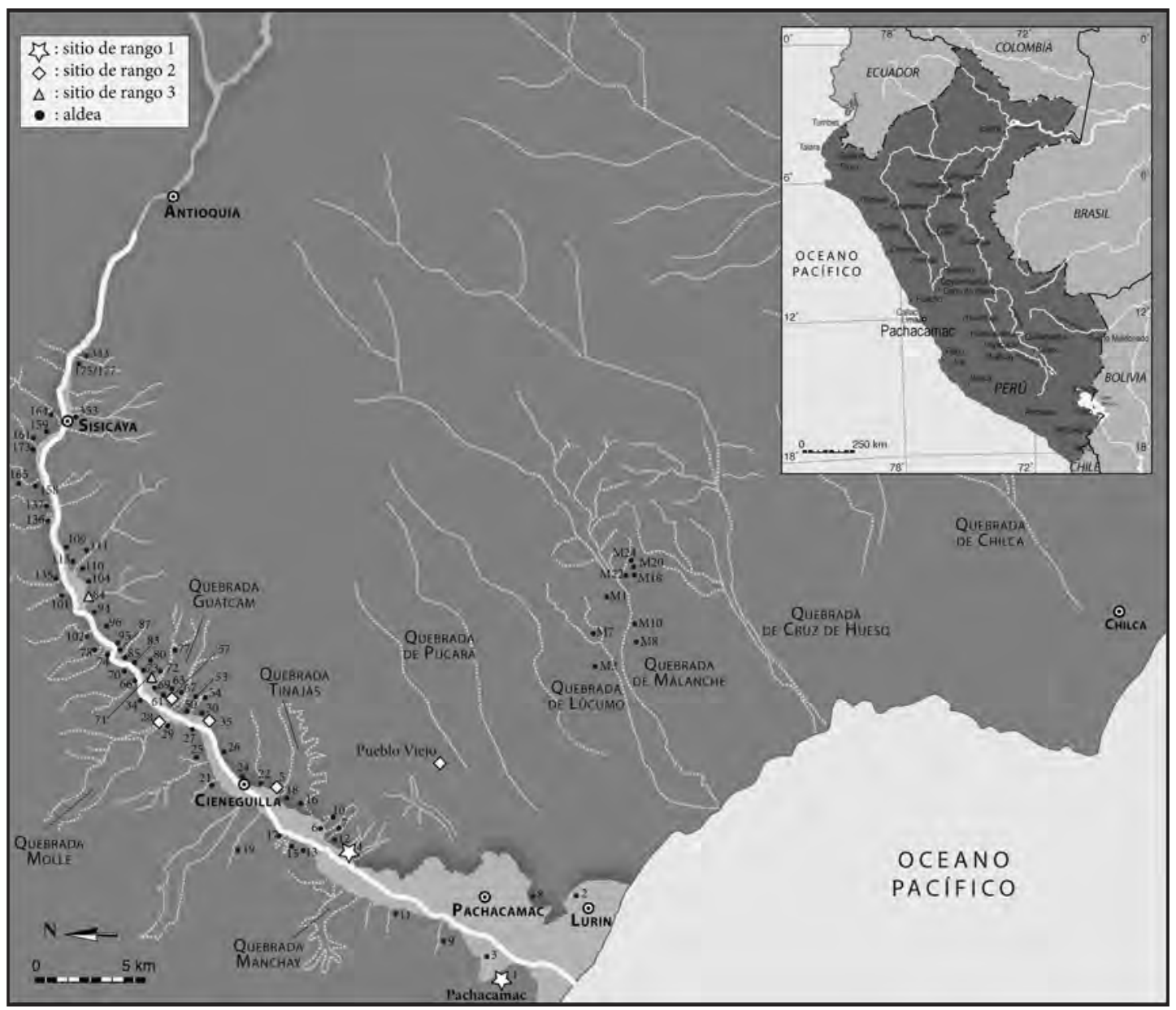

Figura 5.

de Molle. Río Seco y Chontay representan una categoría inferior en la jerarquía del curacazgo de Ychsmaa; sus respectivos "correspondientes" sin duda se encuentran entre las aldeas (Fig.6). Las aldeas se repartían entre los diversos jefes locales, según su grado de autoridad en el valle bajo.

Si comparamos ahora nuestras dos fuentes escritas principales - la vista de Andrade y el testamento de Sabat- con los datos de campo respecto a la distribución y tamaño de los asentamientos, resalta una muy interesante evolución. En efecto, según Andrade, tenemos
3 parcialidades Urin Ychsma, Anan Ychsma y Caringas. Su territorio respectivo se puede ilustrar de la manera siguiente (Fig.7), por lo menos en el curso del periodo Intermedio Tardío. Estos linderos se definieron sonbre la base de criterios arqueológicos, principalmente la distribución proporcional de las ceramicas locales de pasta naranja, marrón o negra (Eeckhout 1999; Feltham 1983, 2005; Feltham y Eeckhout 2004), pero también rasgos arquitectónicos específicos de las culturas costeñas como los patrones de asentamiento, elementos formales distinctivos (como rampas y cenotafos), etc. (Eeckhout 


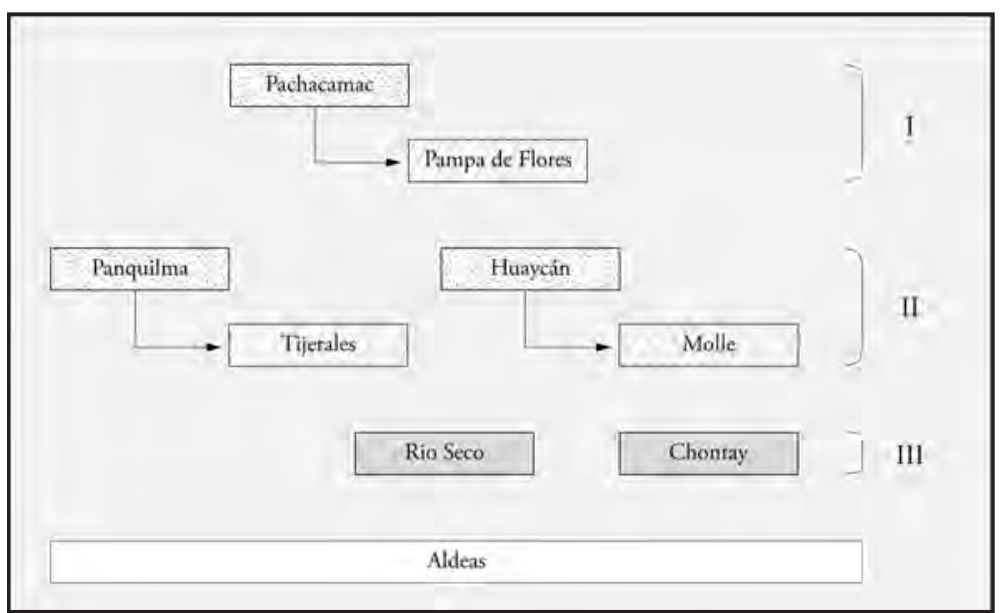

Figura 6.

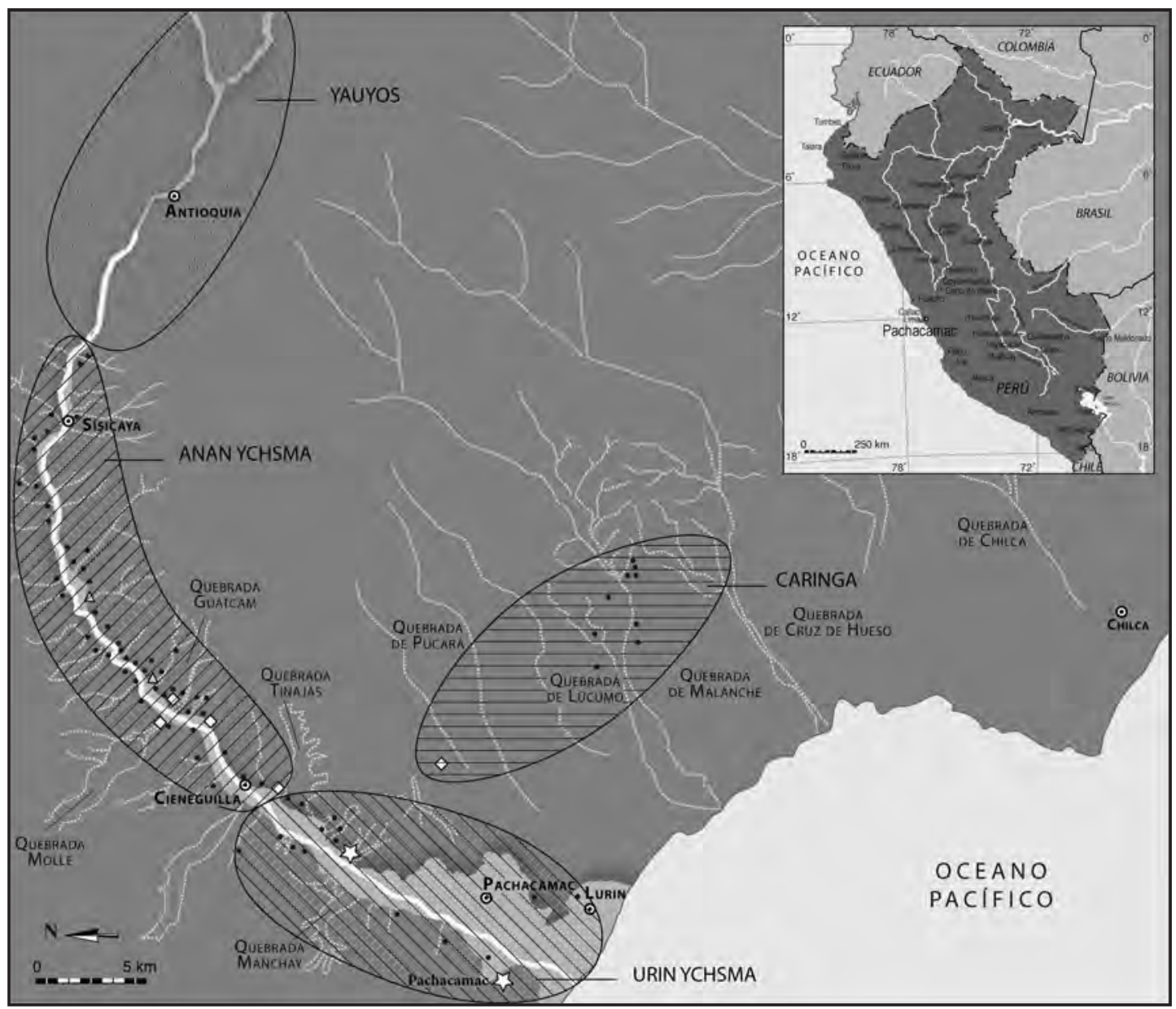

Figura 7. 


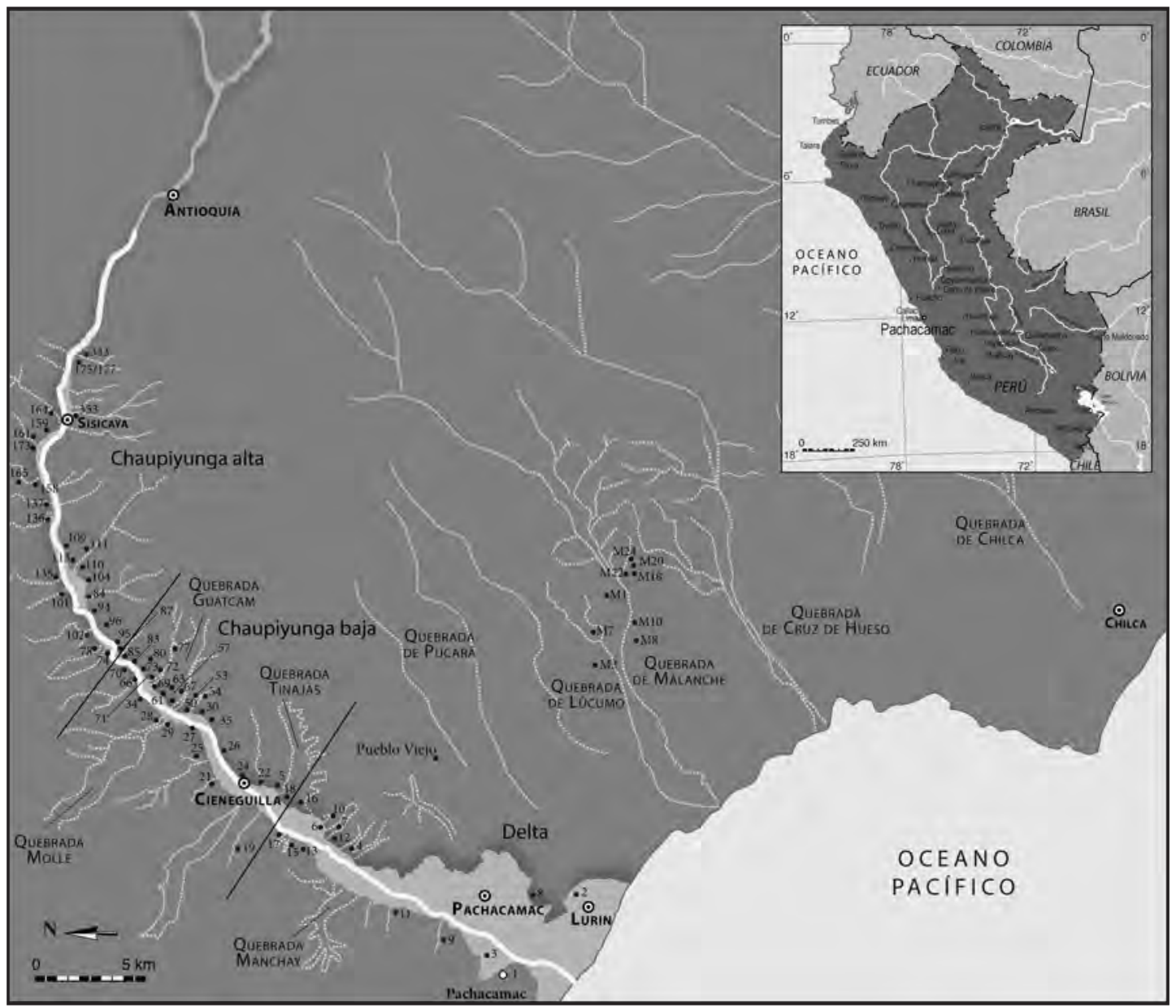

Figura 8.

1999). En efecto, la distribución de los sitios tardíos, del material y de los elementos arquitectónicos sugiere una dicotomía entre valle bajo (desde la costa hasta $700 \mathrm{~m}$ de altitud) y mas alla de $700 \mathrm{~m}$ de altitud.

Para que se pueda contrastar eficientemente esto con los datos etnohistóricos, es necesario por una lado examinar la distribucion de los sitios tardíos para definir núcleos y áreas de probable control. Por otro lado, se debe definir los linderos de los territorios de los ayllus sobre la base de textos. Para precizar estos linderos, la opción más común es de seguir las propuestas de Rostworowski (1978; Cornejo 2000; 2002), es decir el trazo de los canales usados en la época (cf Feltham 1983), pero este principio también puede ser discutido en su aplicación concreta ( $\mathrm{cf}$ Villacorta 2004). Por su lado, Marcone y Lopez Hurtado (2002; Marcone 2004) han sugerido que se tendría que tomar en cuenta el conjunto geográfico-ambiental para sectorizar el valle de Lurín, y concretamente proponen 3 subdivisiones para el valle bajo: el cono de deyección desde la desembocadura del río hasta la altura de la Quebrada Tinajas (200m de altitud); la Chaupiyunga baja desde Tinajas hasta Río Seco $(500 \mathrm{~m})$, y luego la Chaupiyunga alta hasta Sisicaya (900m) (Fig.8). Esta propuesta me pare- 
ce bien sustentada, y el área considerada aquí, sea el valle bajo y sus vestigios, corresponde a estas subdivisiones, sino que parece haber una especie de lindero cultural en el promedio de la Chaupiyunga alta, sea a unos $700 \mathrm{~m}$ de altitud. Esto se revela especialmente interesante, como lo vamos a ver en seguida.

Se debe subrayar que los histogramas para cada una destas zonas son muy coherentes pues muestran que los sitios ychsmas se distribuyen según el principio de jerarquía asimétrica en cada zona y entre cada zona, siendo al parecer la parte Urin la que dominaba a la otra, por lo menos si nos fijamos en el tamaño relativo de los asentamientos (Figs 9, 10).

La esfera de influencia Ychsma, abarcaba pues incialmente estas tres zonas (Fig.7), con los Urin Ychsma en el delta y la costa y los Anan Ychsma en el conjunto de la Chaupiyunga, donde se cultiva -entre otros- la coca. Es probablemente por tener aceso a esta zona ecológicamente muy rica, que los Yauyos serranos invaden poco a poco la Chaupiyunga (Fig.11), tal como se reporta en términos míticos en el manuscrito de Huarochiri, y como se puede observar en los cambios que sufren los sitios Ychsmas de esta zona, conforme avanza el tiempo (Eeckhout 1999; Feltham 2005). Si comparamos esto con los datos etnohistóricos del testamento de Alonso Sabat (Espinoza Soriano 1964, Paredes Botoni 2004), resulta que hay una discrepencia total con el registro arqueológico, pues el único sitio asociado con el ayllu Pachacamac sería el sitio arqueológico del mismo nombre,

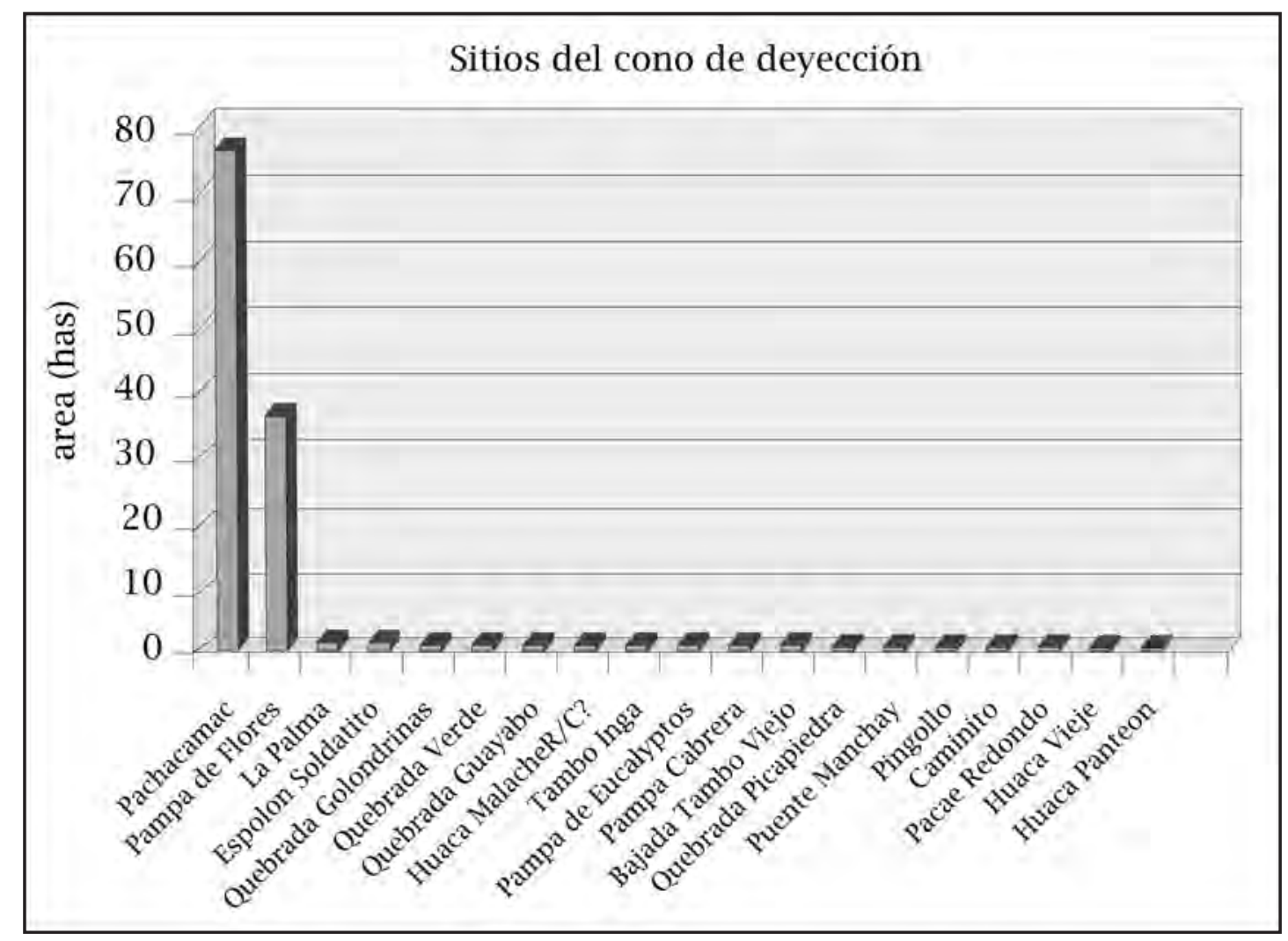

Figura 9. 
Peter Eeckhout Poder y jerarquías ychsmas en el valle de Lurín

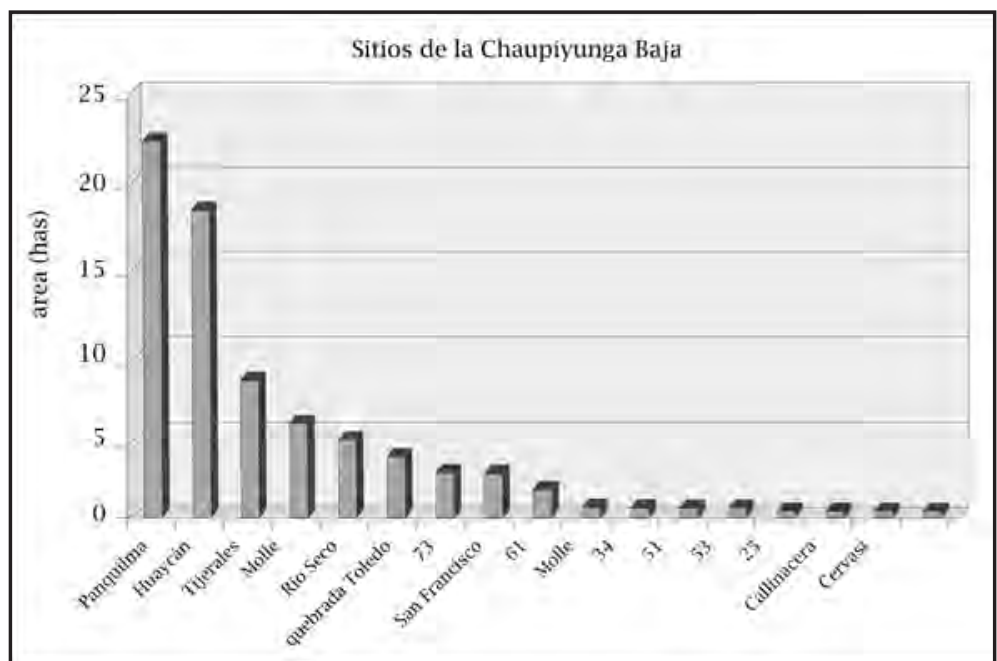

Figura 10.

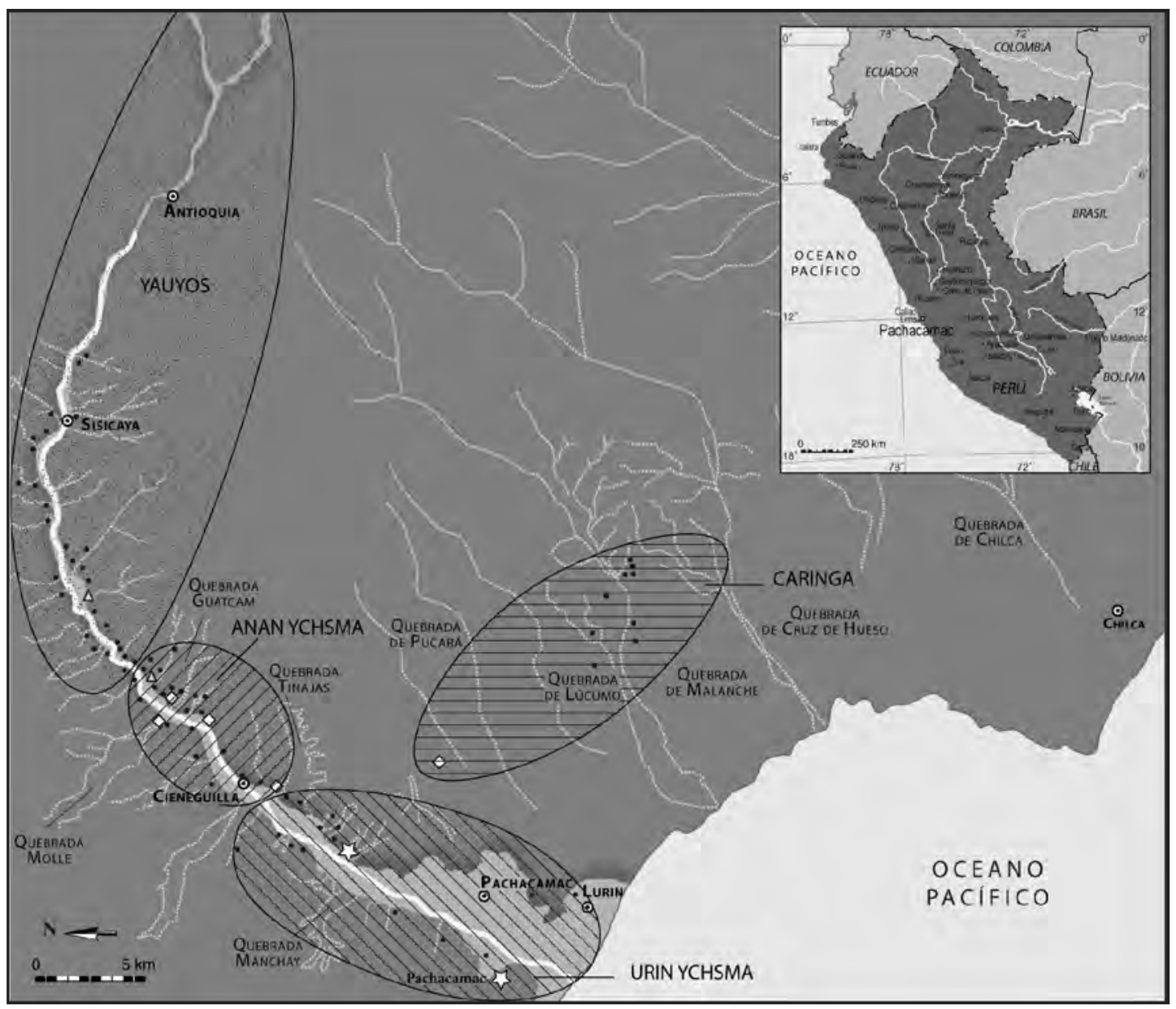

Figura 11. 


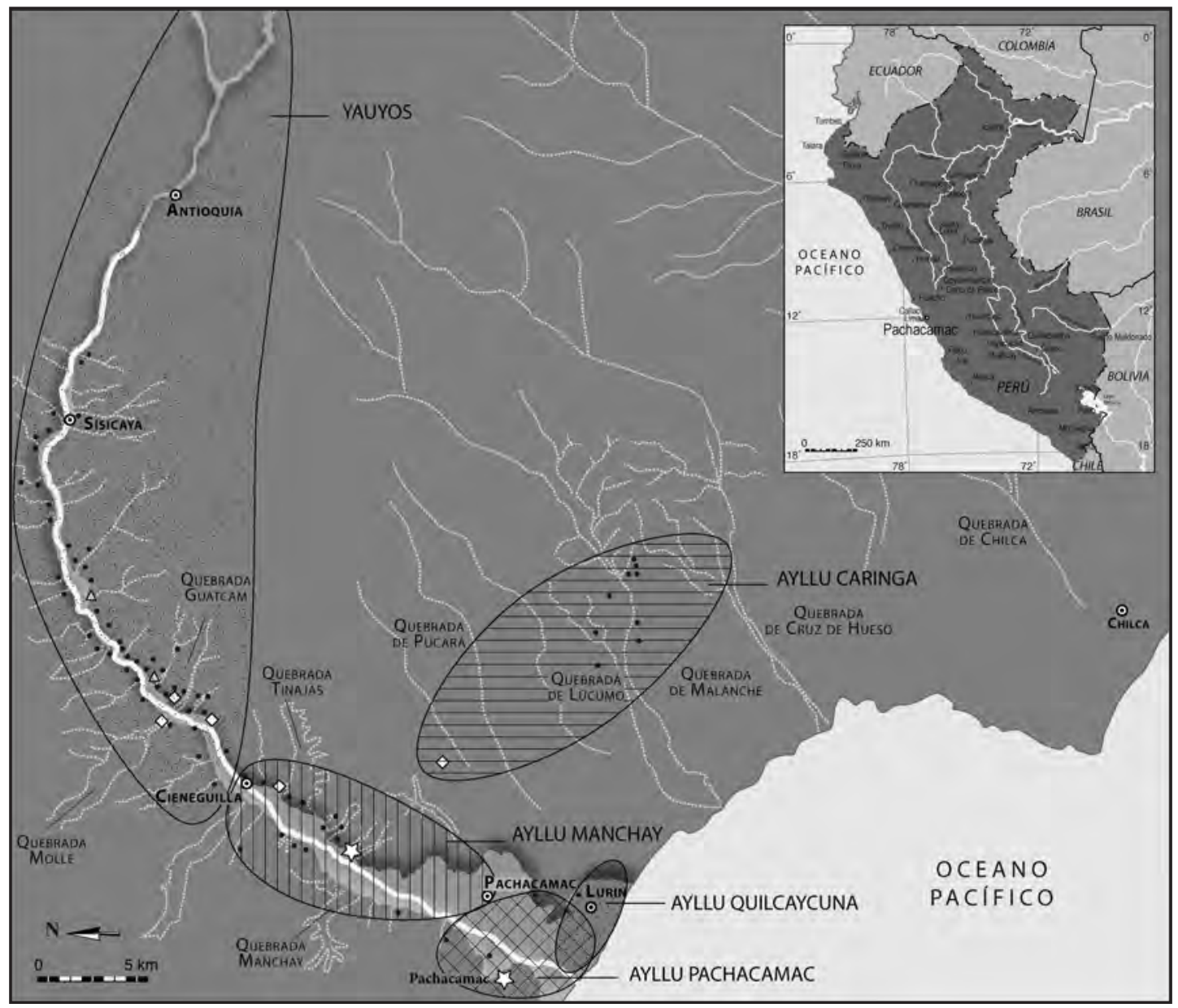

Figura 12.

mientras todos los otros sitios del valle bajo hasta casi $400 \mathrm{~m}$ de altitud hubieran sido ocupados por los Manchay. La parte superior de la Chaupiyunga estaría en manos de los Yauyos, a pesar que incluye sitios que tienen rasgos muy costeños, como Chontay o Río Seco. Yo creo que esta discrepencia ilustra un proceso histórico, sea el análisis de la distribución de los sitios arqueológicos conforme a las divisiones geográficas locales refleja la situación en tiempos de los Ychsmas, es decir, antes de la llegada de los Incas. Una vez que están incluidos en el Tahuantinsuyu, los Ychsmas cambian del todo, hasta de nombre, y los Incas trastornan por completo las estructuras y linderos tradicionales, otorgando territorios ychsmas, a los Yauyos en la zona Chaupiyunga y transformando Pachacamac en un sitio de rango imperial, mas involucrado en la red estatal que en los antiguos liezgos locales. Los Anan Ychsma pues ya no tienen ningun territorio propio, y las subdivisiones sociales que se mantienen son probablemente las que corresponden a los ayllus Urin Ychsma, sea Manchay y Pachacamac -el nuevo nombre que le dan los Incas a los Ychsmas (Fig.12).

Esta situacioñ -probable herencia del Horizonte Tardío- es la que está reflejada en el testamento de Alonso Sabat en 1584. Es interesante 
subrayar que el mismo personaje se presentaba en la visita de Andrade en 1573 como curaca principal de Pachacamac y Caringas, lo que a fin de cuenta resulta muy coherente.

De cierto modo pues, aparece que a lo largo del tiempo se van desaparenciendo los Anan Ychsma al provecho de los Yauyos. Resulta dificil explicar donde residían y a quienes mandaban los personajes que se presentan como caciques de Anan Ychsmas en 1573. Posiblemente los sitios invadidos por los Yauyos serranos tenían una ocupación mixta de Anan Ychsmas y Yauyos, así lo mencionan ciertas fuentes (ver Feltham 2005).

\section{Conclusiones}

La lectura crítica de las fuentes etnohistóricas y el análisis independiente de los datos arqueológicos permiten esbozar una imagen más completa de la jerarquía ychsma del Lurín que el uso separado de estas fuentes. Textos y evidencias de campo nos ayudan a en entender mejor el pasado cuando uno acepta la idea que ambas fuentes son complementarias y que no hay sentido en intentar de "comprobar" la credibilidad de una por la otra, como tantas veces se ha hecho. Aquí vemos que el curacazgo ychsma de Lurín se conformaba de linajes jerarquizadoss, organizados sobre los principios de dualidad y bipartición. Este principio de dualidad jerarquizada se materializaba en la distribución y el tamaño de los asentamientos de la elite, estrechamente ligados a su medio ambiente. Tanto los textos como la arqueología ayudan en percibir los cambios que sufrió esta estructura ancestral por causa de su integración (o mejor dicho desintegración) en una estructrura más amplia, sea el Tahuantinsuyu o el Estado colonial.

Por supuesto, se trata solo de un esbozo, y en términos metodológicos se debe reconocer una serie de elementos que posiblemente afectan los resultados y debilitan las conclusiones.

1. Muestra: los sitios seleccionados son los que quedaban en 1966, época del survey del equipo de Patterson. Es posible sino probable que no refleje de manera completa la situación del pasado

2. Cronología: la atribución cronológica de los sitios y su superficie relativa a lo largo del tiempo, así como su función probable, todo esto y más puede ser precizado, pues la mayoría de ellos no han sido excavados.

3. Inversión de la energía social: Por más que el acceso proporcionado a la fuerza de trabajo según el rango de autoridad aparezca algo lógico, esto no significa que la dicha fuerza de trabajo ha sido empleada de manera uniforme para las estructuras que conforman los sitios donde residían los élites, sino también para otros fines (sistema de irrigación, de defensa, vías de comunicación, etc), incluso tareas que no dejan huellas en el registro material. Hay que considerar pues que la superficie de los sitios como criterio principal de importancia adentro del sistema local de autoridad es una simplificación heurística que podrá ser relativizada solo con el aporte de más datos de todas clases.

4. Diferencia temporal: los documentos describen una situación de fines del siglo XVI, con los trastornos que sufrieron las estructuras locales por causa de la conquista, mientras los sitios pertenecen a los periodos prehispánicos tardíos

Si tenemos en cuenta estos factores limitantes, debemos recalcar que las conclusiones no deben ser consideradas para nada como definitivas, sino simplemente sugerientes para el entendimiento de las estructuras antiguas de autoridad en el valle y su estudio cada vez más profundizado en el futuro.

\section{Agradecimientos}

Agradezco al INC por haber expedido las autorizaciónes de investigación en Pachacamac y el valle de Lurín. El Proyecto Ychsma recibió ayuda financiera de la Université Libre de 
Bruselas, del Fonds National de la Recherche Scientifique y del Fonds de la Recherche Fondamentale Collective (Bélgica), de la National Geographic Society (Washington) y de la Curtiss T. and Mary G. Brennan Foundation (Santa Fe). También recibimos apoyo logístico de parte del Muséo de Sitio de Pachacamac y de la Embajada de Bélgica en el Perú. Quiero agradecer especialmente a Carlos Farfán, codirector nacional del Proyecto Ychsma, así como a Jesús Ramos Giraldo, por su apoyo en las temporadas llevadas en el Lurín. Nathalie Bloch (Centre de Recherches Archéologiques de la ULB) realizó las figuras. Asumo la total responsabilidad del contenido del presente artículo, así como de los errores que podrían existir.

\section{REFERENCIAS CITADAS}

Alborñoz, Cristóbal de

1967 [fin del s. XVI] La Instruccion para Descubrir Todas las Guacas del Piru y sus Camayos yHaziendas. Ver Duviols 1967.

Arriaga, Pablo Josef de

1999 [1621] La Extirpación de la Idolatría en el Pirú. Cuzco: Centro de Estudios Rurales Andinos "Bartolomé de las Casas".

Avila, Francisco de

1987 [1608?] Ritos et Tradiciones de Huarochiri del siglo XVII. Versión paleográfica, interpretación fonológica y traducción al castellano por Gérald Taylor. Instituto de Estudios Peruanos e Instituto Frances de Estudios Andinos, Lima.

Bueno Mendoza, Alberto

1974-75 Cajamarquilla y Pachacamac: Dos Ciudades de la Costa Central del Perú. Boletín Bibliográfico de Antropologia Americana 37 (46): 171-211.

Burger, Richard y Lucy Salazar-Burger

1992 La seconda temporada de investi- gaciones en Cardal, valle de Lurín (1987). In Estudios de Arqueología Peruana, ed. Duccio Bonavia, pp.123. 148. Fomciencias, Lima.

Cornejo, Miguel

2000 La nación ishma y la Provincia inka de Pachacámac. Arqueológicas 24:14772.

2002 Sacerdotes y tejedores en la provincia inka de Pachacamac. Boletín de Arqueología PUCP 6:171-204.

Dávila, Diego

1881 [1586] Descripción y relación de la provincia de los Yauyos toda, Anan Yauyos y Lorin Yauyos. In Relaciones Geograficas de Indias, ed. Marco Jiménez de la Espada, pp.155-165. Biblioteca de Autores Espanoles, T. 188. Madrid.

Duviols, Pierre

1967 Un Inédit de Cristobal de Albornoz : La Instrucción para Descubrir Todas las Guacas del Piru y sus Camayos y Haziendas. Journal de la Société des Américanistes 56(1):7-39.

2003 Procesos y Visitas de Idolatrías. Cajatambo, siglo XVII. Pontificia Universidad Católica del Perú e Instituto Francés de Estudios Andinos, Lima.

Eeckhout, Peter

1997 Pachacamac (Côte centrale du Pérou) : aspects du fonctionnement, du développement, et de l'influence du site durant l'Intermédiaire récent (ca 900-1470). Tesis Doctoral, Facultad de Filosofía y Letras, Université Libre de Bruxelles.

1999a Pachacamac durant l'Intermédiaire récent. Etude d'un site monumental préhispanique de la Côte centrale du Pérou. British Archaeological Reports International Series, 747. Hadrian Books Ltd, Oxford. 
1999b Les sacrifiés de Pampa de las Florès. Contribution archéologique à l'étude du sacrifice humain dans les Andes centrales préhispaniques. Recherches Amérindiennes au Québec 29(2) :7590.

1999c Offrandes funéraires à Pachacamac et Pampa de las Flores. Exemples des relations entre les côtes nord et centrale du Pérou à l'époque pré-inca. Baessler-Archiv Neue Folge 46 : 1-66.

2003 Ancient Monuments and Patterns of Power at Pachacamac, Central Coast of Peru. Beiträge zur Allgemeine und Vergleichenden Archäologie 23 :139182.

2004a (ed.) Arqueologia de la Costa Central del Peru en los Periodos Tardios, Volúmen especial del Boletin del Instituto Francés de Estudios Andinos 33(3).

2004b La sombra de Ychsma. Ensayo introductivo sobre la arqueología de la costa central del Perú en los periodos tardios. In Arqueologia de la Costa Central del Perú en los Periodos Tardíos, ed. Peter Eeckhout, pp.403-425. Volúmen especial del Boletin del Instituto Francés de Estudios Andinos 33(3).

Espinoza, Waldemar

1964 Bosquejo Historico del Pueblo de San Salvador de Pachacamac. In El Valle de Lurín y el pueblo de Pachacamac: cambios sociales y culturales, eds. J. Matos Mar et al., 132-55. Departamento de Antropologia, Facultad de Letras, Universidad Nacional Mayor de San Marcos, Lima.

1974 El Templo Solar de Paramonga y los Acuarios de Pachacamac. Boletin del Instituto Francés de Estudios Andinos 3(3):1-22. Lima.
Feltham, Jane

1983 The Lurin Valley, Peru: AD1000-1532. $\mathrm{Ph}$. D. Diss. Institute of Archaeology, University of London, Londres.

2005 Yungas and Yauyos - The Interface Bteween Archaeology and Ethnohistory as seen from the Lurín Valley. In Wars and Conflicts in Prehispanic Mesoamerica and the Andes, ed. Peter Eeckhout y Geneviève Le Fort, pp128-145. British Archaeological reports International Series 1385, Hadrian Books Ltd, Oxford.

Feltham, Jane, y Peter Eeckhout

2004 Hacia una definición del estilo Ychsma: aportes preliminares sobre la cerámica tardía de la pirámide III de Pachacamac. En Arqueologia de la Costa Central del Perú en los Periodos Tardios, ed Peter Eeckhout, pp.643-680. Volúmen especial del Boletin del Instituto Francés de Estudios Andinos 33(3).

Kendall, Ann

1985 Aspects of Inca Architecture. Description, Function and Chronology (Part 1). British Archaeological Research International Series , 242. Oxford.

Makowski, Krzysztof

2002 Arquitectura, estilo e identidad en el Horizonte Tardío: el sitio de Pueblo Viejo-Pucará, valle de Lurín. Boletín de Arqueología PUCP 6:137-170.

Marcone, Giancarlo

2004 Cieneguilla a la llegada de los Incas. Aproximaciones desde la historia ecológica y la arqueología. In Arqueologia de la Costa Central del Perú en los Periodos Tardios, ed Peter Eeckhout, pp.715-734. Volúmen especial del Boletin del Instituto Francés de Estudios Andinos 33(3). 
Marcone, Giancarlo, y Enrique Lopez-Hurtado 2002 Panquilma y Cieneguilla en la discusión arqueológica del Horizonte Tardío de la costa central. Boletín de Arqueología PUCP 6:375-394.

Matos, José, y J. Portugal (eds)

1964 El Valle de Lurín y el pueblo de Pachacamac: cambios sociales y culturales. Departamento de Antropología, Facultad de Letras, Universidad NacioMoore, Jerry nal Mayor de San Marcos, Lima.

1995 The Archaeology of Dual Organization in Andean South America: A Theoretical Review and a Case Study. Latin American Antiquity 6 (2):16581.

Mujica, Elias

1997 Malanche: poblaciones precoloniales permanentes en las lomas de la costa central del Perú. In Arqueología, Antropología e Historia en los Andes. Homenaje a María Rostworowski, eds Rafael Varón Gabai y Javier Flores Espinoza, pp.200-222. Instituto de Estudios Peruanos, Lima.

Negro, Sandra

1977 Patrones de Asentamiento Pre-Hispanico en el Valle de Lurín. Tesis de Licenciatura, Universidad Ricardo Palma, Lima.

Netherly, Patricia

1990 Out of Many, One : The Organization of Rule in the North Coast Polities. In The Northern Dynasties. Kingship and Statecraft in Chimor, eds Michael E. Moseley \& A. Cordy-Collins, pp46188. Dumbarton Oaks Research Library and Collection, Washington, D.C.

Paredes, Ponciano

1995 Sinopsis arqueológica e histórica del distrito San Pedro de Lurín. Cuaderno de Divulgación Turistica y Ecológica 1. Municipalidad San Pedro de Lurín.

2004 Notas y comentarios respecto a la continuidad de los Señores naturales del linaje de los Savac (Saba) en los padrones y repartimientos de tierras de 1733 y 1787 en el valle de Lurín. En Arqueologia de la Costa Central del Perú en los Periodos Tardíos, ed Peter Eeckhout, pp.735-782. Volúmen especial del Boletin del Instituto Francés de Estudios Andinos 33(3).

Patterson, Thomas

1966 Lurín Valley Survey Notes. Ms en posesión del autor.

Rostworowski, María

1972 Breve Informe sobre el Señorio de Ychma o Ychima. Arqueología PUC 13: 37-51. Instituto Riva-Agüero, Pontificia Universidad Católica del Perú, Lima.

1978 Señorios Indigenos de Lima y Canta.. Instituto de Estudios Peruanos, Lima.

1989 Costa Peruana Prehispánica. Instituto de Estudios Peruanos, Lima.

1992 Pachacámac y el Señor de los Milagros. Una Trayectoria Milenaria. Instituto de Estudios Peruanos, Lima.

1999 El Señorio de Pachacamac. El informe de Rodrigo Cantos de Andrade de 1573. Instituto de Estudios Peruanos, Lima. Salinas y Córdova, Fray Buenaventura de

1957 [1630] Memorial de las historias del Nuevo Mundo. UNMSM, Lima.

Spalding, Karen

1984 Huarochiri. Andean Society Under Inca and Spanish Rule. Stanford University Press, Stanford.

Villacorta, Luis

2004 Los palacios en la costa central durante los períodos tardios: de Pachacamac al Inca. In Arqueología de la Costa Central del Perú en los Periodos Tardios, ed. Peter Eeckhout, pp.539570. Volúmen especial del Boletin del Instituto Francés de Estudios Andinos 33(3). 